\title{
An aeromagnetic survey of Shinmoe-dake volcano, Kirishima, Japan, after the 2011 eruption using an unmanned autonomous helicopter
}

\author{
Takao Koyama $^{1}$, Takayuki Kaneko ${ }^{1}$, Takao Ohminato ${ }^{1}$, Takatoshi Yanagisawa ${ }^{2}$, Atsushi Watanabe ${ }^{1}$, and Minoru Takeo ${ }^{1}$ \\ ${ }^{1}$ Earthquake Research Institute, University of Tokyo, 1-1-1 Yayoi, Bunkyo-ku, Tokyo 113-0032, Japan \\ ${ }^{2}$ IFREE, Japan Agency for Marine-Earth Science and Technology, 2-15 Natsushima-cho, Yokosuka, Kanagawa, Japan
}

(Received November 9, 2012; Revised February 21, 2013; Accepted March 9, 2013; Online published July 8, 2013)

\begin{abstract}
In January 2011, magmatic eruptions at Shinmoe-dake, Kirishima, Japan, started for the first time in 300 years. After three sub-plinian explosive events, lava accumulation started at the summit crater. The accumulation lasted for about three months, and the final volume of the accumulated lava reached $1.5 \times 10^{7} \mathrm{~m}^{3}$. We conducted aeromagnetic surveys using an unmanned autonomous helicopter over the Shinmoe-dake summit crater in late May 2011, and late October to early November, 2011, in order to investigate the magnetization of this area and changes in the magnetic field associated with the 2011 eruption. The averaged magnetization intensity around Shinmoe-dake is $1.5 \mathrm{~A} / \mathrm{m}$. A demagnetized area elongated in the north to northwest direction from Shinmoedake has been detected. We also detected a clear change in the total magnetic field between the two aeromagnetic observations characterized by positive and negative changes in the south and north, respectively, of the Shinmoedake edifice. These changes are well reproduced by a model in which 20-70\% of lava accumulated in the summit crater was cooled down below the Curie temperature and has been magnetized.
\end{abstract}

Key words: Shinmoe-dake 2011 eruption, unmanned aerial vehicle (UAV), helicopter, aero-magnetic survey, magnetization intensity, lava cooling.

\section{Introduction}

In January 2011, the Shinmoe-dake volcano, Kirishima, Japan, began its first magmatic eruption in 300 years. During the intense eruptive activity including three sub-plinian explosive events, lava accumulation occurred at the summit crater. During the lava accumulation for three months, the main phase lasted for about a month. The lava feeding rate was high in the first three days. It was estimated to be $8 \times 10^{6} \mathrm{~m}^{3} /$ day, and the final volume of the accumulated lava reached $1.5 \times 10^{7} \mathrm{~m}^{3}$ by the end of April (Nakada et al., 2013).

In Japan, when an eruption starts at a volcano, there are restrictions on approaching the active vent. For example, at the Sakura-jima volcano, one of the most active volcanoes in Japan, no one is allowed to approach closer than two kilometers from the summit craters. The restriction is imposed not only for ground-based approaches, but also for manned aircraft. This restriction causes data gaps for almost all types of geophysical measurements, including aeromagnetic surveys (e.g., Okubo et al., 2009). Observations near the active summit area is also strictly restricted for Shinmoe-dake.

Before the 2011 eruption, the Earthquake Research Institute, University of Tokyo, had operated five magnetometers around the summit area of Shinmoe-dake. Approaching within three kilometers of the summit of Shinmoe-dake has

Copyright (C) The Society of Geomagnetism and Earth, Planetary and Space Sciences (SGEPSS); The Seismological Society of Japan; The Volcanological Society of Japan; The Geodetic Society of Japan; The Japanese Society for Planetary Sciences; TERRAPUB. been prohibited since the beginning of the eruption in January 2011. By the time of the largest eruptions in late January and early February, 2011, four of five magnetometers were lost, and it was impossible to fix or to replace them because of the restriction. Thus, we needed to construct a substitute geomagnetic observation system in order to monitor the volcanic activity of Shinmoe-dake.

We needed an observation method in which aeromagnetic surveys could be conducted in the summit area without risk to human lives. For this purpose, we used an aeromagnetic survey system based on an unmanned autonomous helicopter. By using this system, we were able to conduct aeromagnetic surveys above the summit crater in late May 2011, and late October through early November, 2011, in order to investigate the magnetization of Shinmoe-dake, and the surrounding area, and changes associated with the 2011 eruption.

An aeromagnetic survey targeting the entire Kyushu area was conducted in 1981 (Okubo et al., 1985), in which the flight path spacing was $3 \mathrm{~km}$ and thus the resolution around Shinmoe-dake was insufficient for our purposes. In that sense, our measurement is the first attempt at a highresolution aeromagnetic survey focusing on Shinmoe-dake. In this paper, we introduce the aeromagnetic survey system using an unmanned autonomous helicopter, following a brief description of the 2011 eruption of the Shinmoe-dake volcano, Kirishima, in Kyushu, Japan. After describing the analysis method and its results, we interpret the obtained magnetization distribution and the change in magnetic field intensity. 

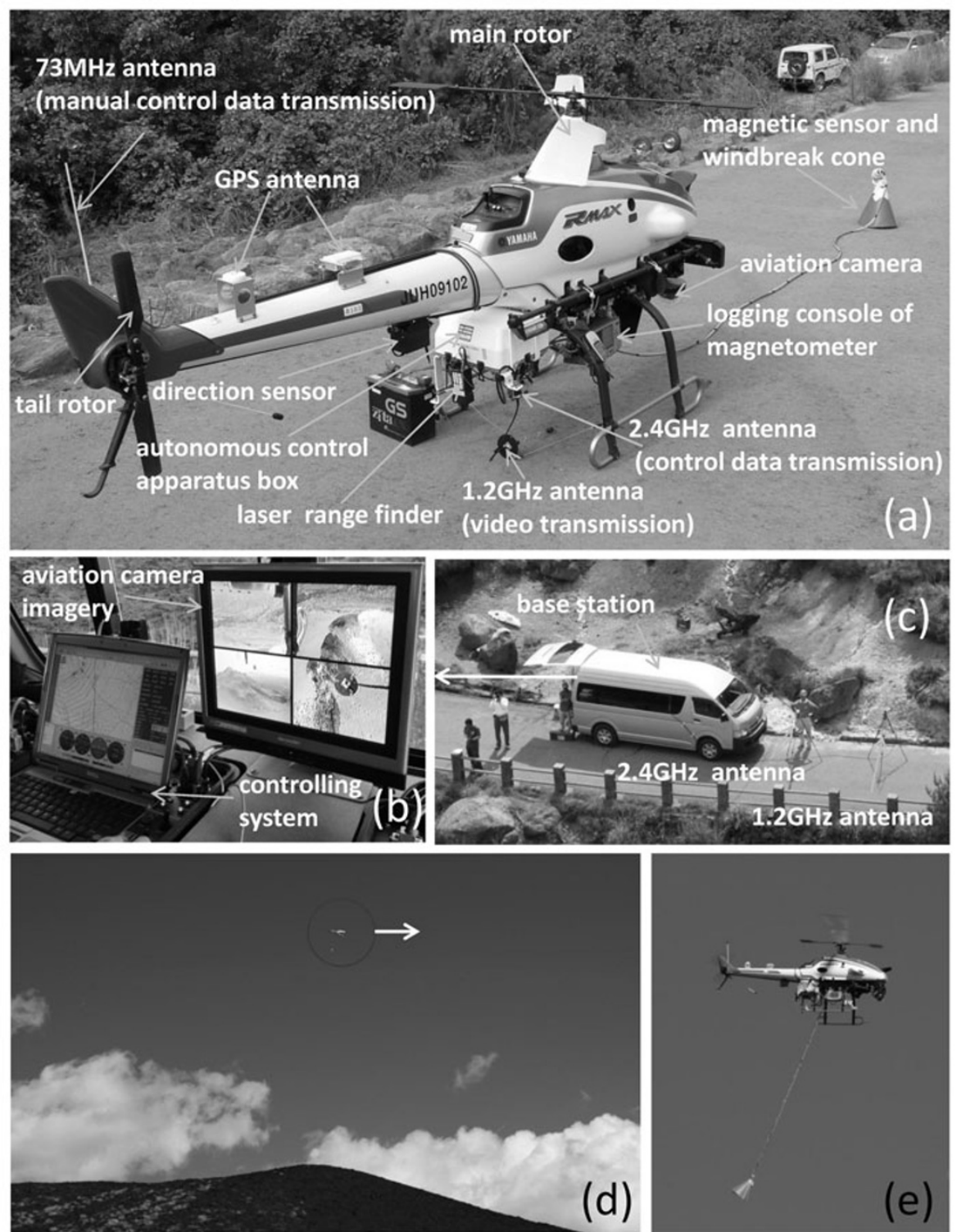

Fig. 1. (a) The main body of the unmanned autonomous helicopter RMAX-G1. (b) Inside the car used for the base station. (c) The car used for the base station with the wireless antennas. (d) A snapshot of the helicopter conducting aeromagnetic observation. (e) A close-up of "(d)". Wire length between the helicopter body and the cesium sensor is $4.5 \mathrm{~m}$.

\section{Unmanned Aerial Vehicle (UAV) for Aeromag- netic Surveys at Active Volcanoes}

2.1 Unmanned autonomous helicopter used for volcano observations

For our volcano observations, we adopt a commercial UAV, model RMAX-G1 (Fig. 1), developed and manufactured by the Yamaha-Motor Co., Ltd. This UAV system consists of a helicopter and a base station (Suzuki, 2005; Kaneko et al., 2011). The main body is 3.6-m long and weighs $84 \mathrm{~kg}$, including fuel and the onboard camera system. The payload of this helicopter is approximately 10 $\mathrm{kg}$. The maximum flight time is approximately 90 minutes, depending on the amount of fuel. The helicopter can fly autonomously along a previously programmed path with meter accuracy, using real-time kinematics differential GPS. The radius of action for autonomous aviation is approximately $5 \mathrm{~km}$ from the base station. The base station consists of a set of antennas, GPS equipment and mobile PCs, and is easily portable. During the flights, the helicopter must be in sight of the base station, so that the wireless communication between the helicopter and the base station using $0.8 \mathrm{GHz}, 1.2 \mathrm{GHz}$ and $2.4 \mathrm{GHz}$ bands is not interrupted. The flight course is prepared beforehand and the helicopter flies along the track specified by the course data transmitted from the base station. It is also possible to change the flight path by transmitting new path information during the flight, or change the flight mode from automatic to manual. The capabilities and specifications of the helicopter are summarized in Table 1.

The advantages of an aeromagnetic survey using an unmanned helicopter is not limited to being risk-free for human lives. There are two other major advantages: one is that an unmanned helicopter can fly at a much lower altitude. Due to the civil aeronautics act in Japan, the lowest flight altitude allowed for manned helicopters is $150 \mathrm{~m}$, while there is no altitude limitation for our unmanned heli- 
Table 1. Capabilities and technical specifications of the unmanned autonomous helicopter model RMAX G1 manufactured by Yamaha Motors Co.

\begin{tabular}{ll} 
& \multicolumn{1}{c}{ Helicopter capabilities } \\
\hline Maximum payload & $10 \mathrm{~kg}\left(1 \mathrm{~atm}, 20^{\circ} \mathrm{C}\right)$ \\
Maximum flight time & $90 \mathrm{minutes}$ \\
Radius of action from the base station & $5 \mathrm{~km}$ \\
Maximum speed & $20 \mathrm{~m} / \mathrm{s}$ \\
Operating temperature range & $-10 \sim+45^{\circ} \mathrm{C}$ \\
Maximum permissible wind speed & $10 \mathrm{~m} / \mathrm{s}($ average $), 15 \mathrm{~m} / \mathrm{s}$ (instantaneous) \\
\hline \multicolumn{1}{c}{ Helicopter technical specifications } \\
\hline Total length & $3.63 \mathrm{~m}$ \\
Maximum width & $0.72 \mathrm{~m}$ \\
Total height & $1.22 \mathrm{~m}$ \\
Weight & $84 \mathrm{~kg}$ (including fuel and camera system) \\
Fuel tank capacity & 11 liters \\
Engine maximum power/torque & $15.4 \mathrm{~kW} / 2.6 \mathrm{~kg}$ m \\
Engine type & water-cooled, two-strokes, \\
& two-cylinder horizontally opposed \\
Radio frequency for autonomous control & $2.4 \mathrm{GHz}$ \\
and data transmission & \\
\hline
\end{tabular}

copter because it weighs less than $100 \mathrm{~kg}$. Since the magnetic field rapidly attenuates as one over the cube of the source-receiver distance, being able to fly at low altitudes is a big advantage for obtaining data with a high signal-tonoise ratio. Another advantage is that the flight path is far more accurate. By conducting aeromagnetic surveys several times using exactly the same path, small changes in the magnetic field, and, thus, small changes in the temperature inside volcanoes, can be detected without being hidden by the noise due to inaccurate flight paths.

\subsection{Cesium magnetometer}

A portable Cesium optical-pumping magnetometer G858 (MagMapper) from Geometrics, Inc., USA, is used in this system. This instrument consists of a sensor and a logging console, which are connected with a 4.5 -m-long cable. For weight saving, the power is supplied from the main body of the helicopter via a DC/DC converter. To avoid magnetic influence from the main body of the helicopter itself, the sensor needed to be placed at least three meters from the helicopter in order to obtain a noise level of less than $10 \mathrm{nT}$ (Kaneko et al., 2011). We adopted a bird-type installation, where a $4.5-\mathrm{m}$-long rope is suspended from the helicopter with a sensor attached at the end. The sensor was placed in a plastic cone in order to insulate it from possible impact at the time of landing (Kaneko et al., 2011).

\subsection{Previous use of unmanned helicopters in aeromag-} netic surveys

As a first application to aeromagnetic surveys of an unmanned helicopter with a cesium magnetometer, we carried out high resolution aeromagnetic measurements at IzuOshima, Japan, which revealed a detailed shallow magmatic structure inside the summit caldera (Kaneko et al., 2010, 2011). This system was also used for surveys of the northern part of Sakurajima in 2010 and 2011. The latest application of this system was at the Tarumae volcano, Hokkaido, Japan (Hashimoto et al., 2012).

\section{Aeromagnetic Measurement at the Shinmoe- dake Volcano}

\subsection{Outline of the Shinmoe-dake volcano}

Shinmoe-dake is one of more than 20 Quaternary eruptive craters, which constitute the Kirishima volcano in southern Kyushu, Japan. Shinmoe-dake is 18,000 years old and its edifice is andesitic-dacitic. In 1716, a large amount of pumice and lithic fragments were thrown from Shinmoedake and formed a thick layer at the eastern foot. In 1959, a pheriatic explosion left a 500-m-long fissure, passing the summit crater and extending to its western flank. Shinmoedake had a crater lake. According to electromagnetic surveys, hydrothermal water flow travels in a southwesterly direction from the summit crater of Shinmoe-dake (Kagiyama et al., 1996).

In January 2011, magmatic eruptions at Shinmoe-dake, Kirishima, Japan, began. It was the first magmatic eruption in 300 years. During the intense eruptive activity, including three sub-plinian explosive events, lava accumulation started at the summit crater. The lava accumulation lasted for about three months. The major phase of lava accumulation was the first month. The lava feeding rate was especially high in the first three days. It is estimated to have been $8 \times 10^{6} \mathrm{~m}^{3} /$ day, and the final volume of the accumulated lava reached $1.5 \times 10^{7} \mathrm{~m}^{3}$ (Nakada et al., 2013).

\subsection{Aeromagnetic measurements in May 2011}

On May 22, 2011, we conducted an aeromagnetic survey at Shinmoe-dake. We measured the total geomagnetic intensity at $10 \mathrm{~Hz}$ by using the optically-pumped cesium magnetometer described in Subsection 2.2. Flight altitude was fixed at approximately $100 \mathrm{~m}$ above the ground, i.e. it was a draped magnetic survey. Figure 2 shows a bird's eye view of the flight path over Shinmoe-dake as seen from the direction of the base station. The base station of the helicopter was in the Shin-yu area, $3 \mathrm{~km}$ southwest of Shinmoedake's summit (Fig. 3). The horizontal interval between flight paths was also fixed to be $100 \mathrm{~m}$ along most of the flight path, except over the summit crater. Flight velocity 


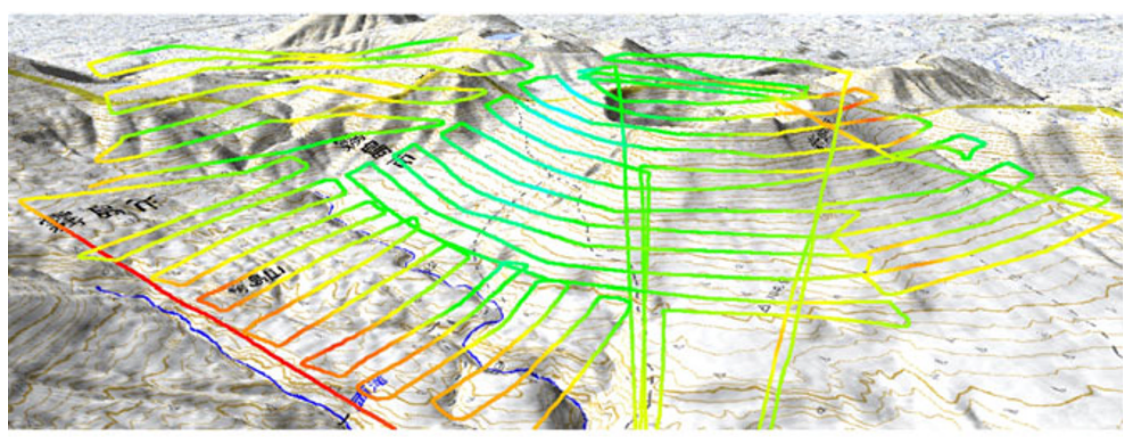

46000nT

$47500 \mathrm{nT}$

Fig. 2. A bird's eye view of the flight path over Shinmoe-dake in the May survey, seen from the southwest, where the base station was located. The colors of the flight path indicate the raw total magnetic field, with warmer colors corresponding to higher intensities. Note that along the majority of the flight path, the flight altitude was lower than the highest elevation of the Shinmoe-dake summit. That is why we had to use Eq. (3) rather than Eq. (2).
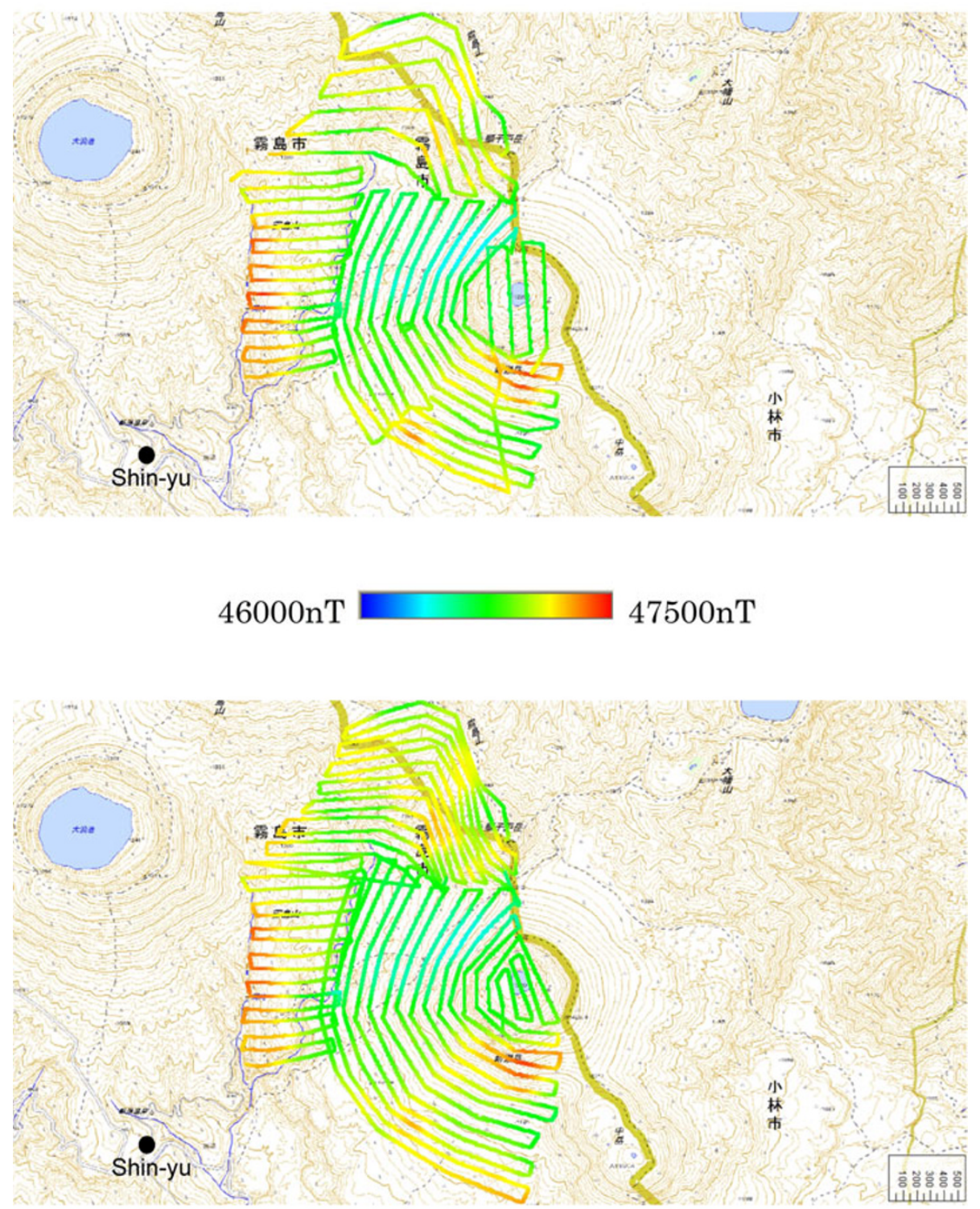

Fig. 3. Top: a schematic of the total magnetic field over Shinmoe-dake measured in the first observation in May, 2011. The colors of the flight paths indicate the intensity of the total magnetic field. (See the color bar legend.) The extent of the survey area is $2 \mathrm{~km}$ by $3 \mathrm{~km}$ (east-west by north-south), Bottom: a schematic of the total magnetic field over Shinmoe-dake taken in the second observation in October and November, 2011. The color legend is the same as in the top panel. Flight paths in the two observations are not identical, though the areas covered are. 
was $10 \mathrm{~m} / \mathrm{s}$. Total flight length was $85 \mathrm{~km}$, which covered a rectangular area 2-km wide in the east-west direction and 3$\mathrm{km}$ wide in the north-south direction, including the summit of Shinmoe-dake. For the safety of the helicopter, the time it could spend above the crater had to be as short as possible during this measurement. Thus, the flight path interval over the crater was larger than elsewhere (Fig. 3, top).

\subsection{Aeromagnetic measurement in October and} November, 2011

On October 31, and November 8, 2011, we again conducted an aeromagnetic survey over Shinmoe-dake. The flight conditions were almost identical to those of the May aeromagnetic survey. We again measured the geomagnetic total intensity at $10 \mathrm{~Hz}$, using the same magnetometer. Although the flight path was not exactly the same as for the May survey due to the difference in weather conditions, the area covered during the October-November survey is the same as in May (Fig. 3, bottom). We slightly modified the flight path so that the areas covered by coarse intervals due to bad weather conditions in May had denser flight intervals.

\section{Data Processing}

By using the magnetic total intensity data obtained by the autonomous unmanned helicopter surveys, the rock magnetization intensity around the Shinmoe-dake edifice was estimated following the three steps explained below.

\subsection{Step 1: Extraction of the magnetic field originating from the magnetized rock}

The raw magnetic field obtained by the helicopter $F_{H}$ (Fig. 3) consists of the main field of the Earth's core, $F_{0}$, the external magnetic disturbance due to solar activity, $d F_{T}$, and the field of the rock magnetization, $d F_{R}$. The last one, $d F_{R}$, is the focus of this study. The geomagnetic total intensity field is related non-linearly to the magnetization. However, since the main field is dominant and uniform in direction inside the survey area, the magnetic total intensity anomalies can be approximated by the component of the magnetic field parallel to the main field. This assumption has commonly been used in many geomagnetic studies (e.g., Ueda, 2007). By adopting this assumption, the magnetic total intensity anomalies can be approximated well to be linearly related to the magnetization, following the Poisson equation:

$$
F_{H}(\mathbf{r}, t)=F_{0}(\mathbf{r})+d F_{T}(\mathbf{r}, t)+d F_{R}(\mathbf{r}),
$$

where $\mathbf{r}$ and $t$ are the observed position and time, respectively. The main field $F_{0}$ and the field due to rock magnetization, $d F_{R}$, can be regarded to be constant in time during the relatively short survey periods. To retrieve $d F_{R}$ from $F_{H}, F_{0}$ and $d F_{T}$ must be known. $F_{0}$ is estimated by using the 11th Generation International Geomagnetic Reference Field (International Association of Geomagnetism and Aeronomy, 2010). $F_{0}$ has a large wavelength at the Earth's surface, and thus the main field orientation was taken to be the same over the entire survey area. We estimate $d F_{T}$ using independently obtained magnetic field data from another reference magnetometer. In the survey area, we installed another magnetometer near Shin-yu temporarily to obtain the reference field data. We calculate $d F_{T}$ to be the temporal change from the averaged magnetic field at midnight. Actually, the $K$ indices at the Kakioka observatory in Japan were 0 or 1 during the survey period; in other words, there was little magnetic activity (Kakioka observatory, unpublished observations). Therefore, as $F_{0}$ and $d F_{T}$ are known, $d F_{R}$ can be calculated from the observed field $F_{H}$ using Eq. (1). Hereafter, we use the decimated data from $10 \mathrm{~Hz}$ to $0.2 \mathrm{~Hz}$.

\subsection{Step 2: Estimation of the averaged magnetization} intensity around Shinmoe-dake

By using the anomalous magnetic intensity $d F_{R}$, the rock magnetization underground can be estimated. As a second step, the averaged magnetization over the whole survey area is estimated under the approximation that the orientation of the rock magnetization is parallel to the direction of the main field, and also that the magnetization is uniform vertically from the ground surface down to $6 \mathrm{~km}$ below sea level (BSL), which is slightly shallower than the Curie point depth (Okubo et al., 1985). For the surface topography, we use the 10-m-mesh DEM data published by the Geographical Survey Institute Japan. The whole area is divided into elemental magnetization prisms extending in the vertical direction. Each prism has a horizontal size of $10 \mathrm{~m}$ by $10 \mathrm{~m}$ and extends from the ground surface to $6000 \mathrm{~m}$ BSL. We then calculate the contribution of each prism to the total magnetic intensity using the analytical expression below. By summing up the contributions of all prisms, we are able to calculate the total magnetic anomaly. Finally, the averaged magnetization is calculated using the least squares method.

We usually use the following formula introduced by Bhattacharyya (1964) for the analytical expression of the contribution of a magnetization prism to the magnetic total intensity anomaly:

$$
\begin{aligned}
\frac{F(x, y, 0)}{I_{p}}= & {\left[\frac{\alpha_{23}}{2} \log \left(\frac{r_{0}-\alpha_{1}}{r_{0}+\alpha_{1}}\right)+\frac{\alpha_{13}}{2} \log \left(\frac{r_{0}-\beta_{1}}{r_{0}+\beta_{1}}\right)\right.} \\
& -\alpha_{12} \log \left(r_{0}+h\right) \\
& -l L \tan ^{-1}\left(\frac{\alpha_{1} \beta_{1}}{\alpha_{1}^{2}+r_{0} h+h^{2}}\right) \\
& -m M \tan ^{-1}\left(\frac{\alpha_{1} \beta_{1}}{r_{0}^{2}+r_{0} h-\alpha_{1}^{2}}\right) \\
& \left.+n N \tan ^{-1}\left(\frac{\alpha_{1} \beta_{1}}{r_{0} h}\right)\right]\left.\left.\right|_{\alpha_{l}} ^{\alpha_{u}}\right|_{\beta_{l}} ^{\beta_{u}}
\end{aligned}
$$

We use the notation of equation (10) in Bhattacharyya (1964). The fourth and the fifth terms in the R.H.S. of Eq. (2) contain $h$, which is the height of the observation point relative to the height of the position in the magnetization prism under consideration. In a conventional aeromagnetic survey in which the airplane flies high enough over the point of the highest elevation in the survey area, this term $h$ is always positive and thus the fourth and fifth terms are appropriate. In our study, however, the situation is different. Since the unmanned helicopter flies $100 \mathrm{~m}$ above the ground, the majority of the flight paths are lower than the highest point in the survey area: the summit of Shinmoedake. In this case, since the denominators change their 
sign irregularly for every corner of a prism, the fourth and fifth terms in the R.H.S. should have additional constants of either $+\pi$ or $-\pi$. Thus, a simple application of Bhattacharyya's formula, Eq. (2), to our problem may lead to the wrong estimate of the magnetic field.

In order to avoid this problem, we adopt a different formula by Kunaratnam (1981), in which special consideration of the sign of each term in $\tan ^{-1}$ is not required:

$$
\begin{aligned}
\frac{F(x, y, 0)}{I_{p}}= & {\left[\frac{\alpha_{23}}{2} \log \left(\frac{r_{0}-\alpha_{1}}{r_{0}+\alpha_{1}}\right)+\frac{\alpha_{13}}{2} \log \left(\frac{r_{0}-\beta_{1}}{r_{0}+\beta_{1}}\right)\right.} \\
& -\alpha_{12} \log \left(r_{0}+h\right)+l L \tan ^{-1}\left(\frac{h \beta_{1}}{r_{0} \alpha_{1}}\right) \\
& +m M \tan ^{-1}\left(\frac{\alpha_{1} h}{r_{0} \beta_{1}}\right) \\
& \left.+n N \tan ^{-1}\left(\frac{\alpha_{1} \beta_{1}}{r_{0} h}\right)\right]\left.\left.\right|_{\alpha_{l}} ^{\alpha_{l}}\right|_{\beta_{l}} ^{\beta_{u}}
\end{aligned}
$$

The estimated averaged magnetization intensity of Shinmoe-dake is about $1.5 \mathrm{~A} / \mathrm{m}$ for both data obtained in the first experiment in May and the second experiment in October and November. By subtracting the magnetic field due to the averaged magnetization intensity from the magnetic field $d F_{R}$ obtained in the previous step, we obtain the residual magnetic field. This residual field is used in the next step to estimate the horizontal distribution of the magnetization intensity.

\subsection{Step 3: Estimate of the horizontal distribution of the magnetization intensity}

In this section we estimate the horizontal distribution of the magnetization intensity under the assumption that the magnetization of each prism is uniform in the vertical direction. We assume furthermore that each prism is magnetized in the same direction as the present-day Earth's magnetic field. Here, we again use prisms of $10 \mathrm{~m}$ by $10 \mathrm{~m}$ on a horizontal grid, but the model parameters and magnetization intensity are distributed on a $50 \mathrm{~m}$ by $50 \mathrm{~m}$ mesh. By summing up the contributions from all the magnetization prisms, we estimate the magnetization intensity distribution at the 50-m horizontal grid points. To estimate the magnetization intensity distribution, we follow the least squares equation with the norm-minimum regularization term:

$$
\Phi(\mathbf{m})=\Phi_{d}+\lambda \Phi_{m}=\|\mathbf{d}-A \mathbf{m}\|^{2}+\lambda\|\mathbf{m}\|^{2},
$$

where $\Phi(\mathbf{m})$ is the objective function to be minimized, $\Phi_{d}$ and $\Phi_{m}$ are the data misfit and model roughness, respectively, $\mathbf{d}$ is the array of the total intensity anomaly data, $\mathbf{m}$ is the array of the magnetization anomaly model deviated from the averaged magnetization, and $A$ is a Jacobian matrix derived from Eq. (3), which is a full matrix. When the number of data and the number of model parameters are $N$ and $M$, respectively, $A$ is an $N$ by $M$ matrix. A nonnegative value $\lambda$ is a hyper-parameter. Therefore, optimal model parameters $m_{o}$ can be estimated as:

$$
\mathbf{m}_{o}=\left(A^{T} A+\lambda I\right)^{-1} A^{T} \mathbf{d},
$$

where the superscript $T$ stands for a matrix transpose.
In general, calculation of an inverse matrix is a difficult method for solving an inverse problem numerically. To obtain just a single solution $\mathbf{m}$, an iterative method, such as, say, a conjugate gradient (CG) method, is definitely faster and thus more useful. That is why conventional studies have commonly used the CG method (e.g., Nakatsuka, 1995; Ueda, 2007). In this study, however, we use a direct method, the singular value decomposition (SVD). The reason why we chose SVD rather than CG is not only that the size of the problem was feasible for our computational environment, but also that the diagonal elements of the resolution matrix could be easily obtained by the SVD method (e.g., Menke, 1989).

The matrix $A$ is decomposed into:

$$
A=U \Lambda V^{T},
$$

where $U$ and $V$ are orthogonal matrices of order $N$ and $M$, respectively. $\Lambda$ is a $N$-by- $M$ diagonal matrix. Actually, only the first $\min (N, M)$ columns of all the three matrices are used in the following calculations. Equation (5) can be rewritten as:

$$
\mathbf{m}_{o}=V\left(\Lambda^{T} \Lambda+\lambda I\right)^{-1} \Lambda^{T} U^{T} \mathbf{d} .
$$

Once $V, U$ and $\Lambda$ are known, the optimal model parameter vector $\mathbf{m}_{o}$ can easily be calculated for an arbitrary hyperparameter $\lambda$, since $\Lambda$ is diagonal. We can also calculate $\Phi$, $\Phi_{d}$, and $\Phi_{m}$ easily. Using $V, \Lambda$, and $\lambda$, the model resolution matrix $R$ can be expressed as follows:

$$
\begin{aligned}
R & =\left(A^{T} A+\lambda I\right)^{-1} A^{T} A \\
& =V\left(\Lambda^{T} \Lambda+\lambda I\right)^{-1} \Lambda^{T} \Lambda V^{T} .
\end{aligned}
$$

The diagonal components of $R$, which simply indicate the model resolution, are given by:

$$
R_{i i}=\sum_{j} V_{i j} \frac{\Lambda_{j j}^{2}}{\Lambda_{j j}^{2}+\lambda} V_{i j},
$$

where $X_{k l}$ is a $k$ th-column and $l$ th-row component of a matrix $X$. The diagonal component of $R$ can be obtained very quickly using matrices $V$ and $\Lambda$. It turns out that all the calculations can be done one or two orders of magnitude faster than for the iterative methods. This is the main reason why we have chosen SVD instead of CG in this study. Note that the full matrix $R$ cannot always be calculated quickly, but this method avoids the need to calculate it.

The optimal hyper-parameter $\lambda$ is determined by minimizing ABIC (Akaike, 1980):

$$
\begin{aligned}
\operatorname{ABIC}(\lambda)= & N \log \Phi(\mathbf{m})+\sum_{i=1}^{M} \log \left(\Lambda_{i i}^{2}+\lambda\right) \\
& -M \log \lambda+\text { Const. }
\end{aligned}
$$

We calculate the ABIC values as a function of $\lambda$, omitting the constant term in Eq. (10). We also calculate a tradeoff curve between the data misfits and model roughness. A model corresponding to the optimal $\lambda$ that minimizes ABIC is located at the L-shaped corner of the trade-off 
(a)

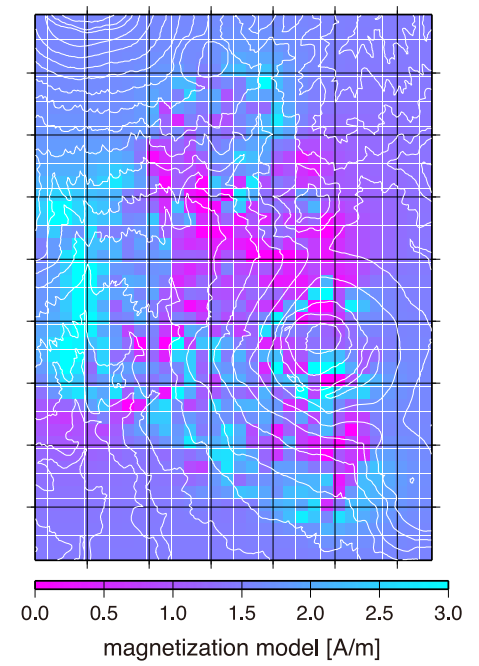

(b)

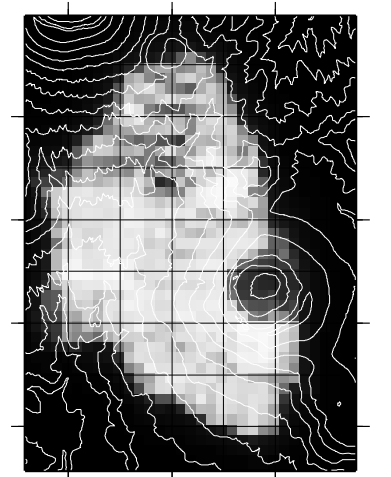

0.00 .10 .20 .30 .40 .50 .60 .70 .80 .91 .0 model resolution

(c)

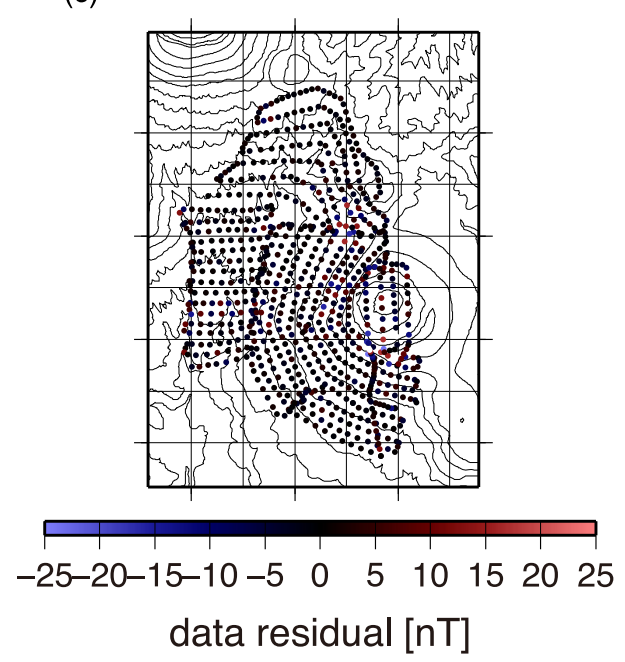

Fig. 4. (a) A schematic of the estimated magnetization for the first survey in May 2011. Colors from red to blue stand for weak to strong magnetization. The average magnetization intensity is $1.5 \mathrm{~A} / \mathrm{m}$. A weakly-magnetized area extends to the north and northwest of Shinmoe-dake. (b) Model resolution. Depending on the spatial density and the altitude of the flight paths, the resolution varies from area to area. Lighter areas correspond to a higher resolution. Northwest of Shinmoe-dake the resolution is lower due to sparser flight paths. (c) Data residual. Red and blue color dots stand for positive and negative residuals, respectively. Dots of darker colors correspond to small residuals. In almost all of the survey area, residuals are less than $10 \mathrm{nT}$. curve. This implies that the model we chose is optimal not only from the viewpoint of minimum ABIC, but also for parameter regularization for an ill-posed discrete linear problem (Hansen, 1992).

Figure 4(a) shows the resulting distribution of the magnetization intensity (mean magnetization intensity plus differential intensity) over the survey area. The model resolution, i.e., the diagonal component of the model resolution matrix $R$, and the residuals are shown in Fig. 4(b) and (c). There are 792 and 1408 data and model parameters, respectively. The low resolution over the crater is due to a larger flight interval and higher flight altitude there.

The use of horizontally larger prisms with several depth intervals may be more realistic. However, there is a large ambiguity in inverting the potential field to obtain the magnetic anomaly distribution. The ambiguity is especially large in the vertical direction. We note that the horizontal anomaly pattern does not change significantly as a function of prism height, only the bulk magnetization value of each prism does. We therefore decided to focus on elucidating the horizontal distribution of the magnetic anomaly, by using prisms that were small in the horizontal directions.

\section{Results and Discussion}

\subsection{Averaged magnetization intensity and the magma} supply path

As explained in Subsection 4.2, the estimated averaged magnetization intensity of Shinmoe-dake is about $1.5 \mathrm{~A} / \mathrm{m}$. The magnetization intensity reflects the content of magnetic minerals in the rock. In general, mafic rocks show a higher intensity, and silicic rocks show a lower intensity. The average magnetization of the dacitic Unzen volcano in Kyushu, Japan, is 2.9-3.1 A/m (Nakatsuka, 1994; Okubo et al., 2005). In Izu-Oshima, a typical basaltic volcano located $100 \mathrm{~km}$ south of Tokyo, Japan, the average magnetization is 10.4-12.1 A/m (Ueda, 2007). The expected magnetization intensity at Shinmoe-dake would be between these two values (3-12 A/m), since (1) Shinmoe-dake is mainly covered with andesitic rock (Imura and Kobayashi, 2001), and (2) the $\mathrm{SiO}_{2}$ variation of the ash emitted in the 2011 eruption is 57-58 wt\% (Suzuki et al., 2013b). This idea is also supported by laboratory measurements, showing that the magnetization values of andesite rock from Shinmoe-dake sampled before the 2011 eruption were between 2.3 and 10.0 $\mathrm{A} / \mathrm{m}$ (Utada et al., 2000). Thus, the estimated value of 1.5 $\mathrm{A} / \mathrm{m}$ is lower than expected based on rock properties alone.

Shinmoe-dake is predominantly built of hot andesitic lava, which cools in situ and acquires a magnetization parallel to the Earth's field. As mentioned above, this seems to contradict the rather low magnetization. What processes can reduce the magnetization of Shinmoe-dake?

The basaltic Stromboli volcano in Italy has an average magnetization intensity of $2.2 \mathrm{~A} / \mathrm{m}$, which is lower than expected for basaltic rocks. It is commonly believed that the magnetic properties of the edifice of Stromboli are affected by past and ongoing volcanic activity (Okuma et al., 2009). Similarly, at Shinmoe-dake, volcanic activity is ongoing and its edifice is covered with relatively new volcanic ash. This may partially explain the low magnetic intensity there.

Could the explanation lie with reverse-magnetized lava 


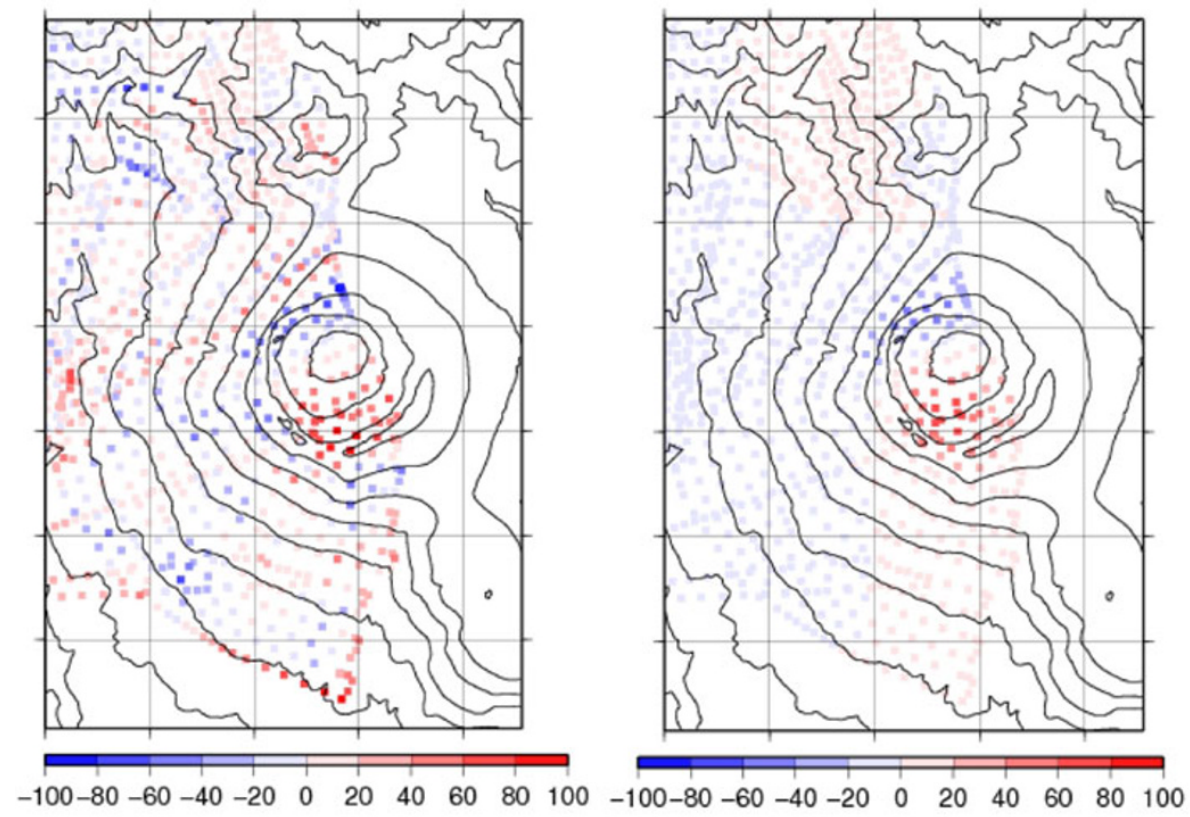

Fig. 5. Left: the difference in the total magnetic field between the second and the first aeromagnetic surveys. Positive and negative magnetic anomalies are seen to the south and north of the volcano, respectively. The amplitude of the anomaly is approximately $100 \mathrm{nT}$. Right: Computed magnetic anomalies, assuming that all $1.5 \times 10^{7} \mathrm{~m}^{3}$ of the lava in the summit crater of Shinmoe-dake acquired a magnetization of $1.5 \mathrm{~A} / \mathrm{m}$ by cooling. Note that the computed total magnetic field accurately explains the observed change.

flows embedded in normally magnetized ones? Shinmoedake was formed as little as 20,000 years ago, thus, there is no reverse-magnetized material there. Another possibility is a locally shallow Curie point depth due to a shallow heat source. Okubo et al. (1985) reported that the Curie point depth in the Kirishima region is $7-8 \mathrm{~km}$ below sea level. Although this depth is shallower than that of the surrounding area, it is highly unlikely that the average depth in the entire area is as shallow as 2 or $3 \mathrm{~km}$. Such a shallow depth may be possible only in a small area.

A more plausible explanation of low magnetization would be post-eruption alteration. For example, low magnetization observed at Hawaii is partially explained by rock alteration (Hildenbrand et al., 1993). The resistivity structure beneath Shinmoe-dake is characterized by a shallow low-resistive layer of $2-10 \Omega \mathrm{m}$ with thickness of 1 $\mathrm{km}$. This low resistivity layer is thought to be an aquifer (Kagiyama et al., 1996). Hydrothermal alteration would occur in such an aquifer. A reduced magnetization layer produced by the alteration of magnetic minerals (such as magnetite) to nonmagnetic minerals (such as hematite) may explain the observed low magnetization at Shinmoe-dake.

As shown in Fig. 4(a), the horizontal distribution of magnetization demonstrates that a weakly-magnetized zone extends from the edifice of Shinmoe-dake in both the north and the northwest directions. The location of the main magma reservoir that supplied the erupted magma to Shinmoe-dake is estimated from GPS observations $6 \mathrm{~km}$ northwest from the summit of Shinmoe-dake at a depth of 9 km (e.g., Imakiire and Oowaki, 2011; Nakao et al., 2012). The GPS observations also suggest that there is another shallow magma reservoir at a depth of 3-5 km beneath the Shinmoe-dake summit (Imakiire and Oowaki, 2011). The geometrical configuration of the two magma reservoirs sug- gests that there is a magma path that connects these two reservoirs. Since a weakly-magnetized area extends northwest from Shinmoe-dake along the inferred magma path, it is highly likely that this weakly-magnetized area is the result of heating from the magma transported from the main deep magma reservoir to the shallow magma reservoir beneath Shinmoe-dake.

\subsection{Lava cooling model}

We compare the total magnetic fields obtained in the two surveys. Using the distribution of magnetization intensity obtained in the first survey (Fig. 4(a)), we can compute the theoretical total magnetic field at each observation point in the second survey. This magnetic field corresponds to the field that is expected along the flight path used for the second survey for the same magnetization distribution as in the first survey. We then subtract the total magnetic field of the first survey from the theoretical total magnetic field for the second survey. Figure 5(left) shows the difference in the total magnetic field between the two surveys. If there is any significant change in the differential total magnetic field, we can interpret such a difference as due to the change in the magnetization distribution compared to the first survey.

The most significant difference in the total magnetic field between the aeromagnetic measurement in May and that in October-November is a combination of positive and negative anomalies on the southern and northern slopes, respectively. The intensity of the magnetic anomaly is $\pm 100 \mathrm{nT}$. A combination of positive and negative anomalies in the north and south of a volcanic edifice is often observed in active volcanoes, and is interpreted as magnetization or demagnetization associated with the ascent or withdrawal of magma. For example, the Aso volcano in Japan often shows this type of anomaly associated with volcanic activity (e.g., Tanaka, 1993). The interpretation of this type of anomaly 
is as follows. When magma approaches the ground surface, the temperature of the volcanic edifice increases by hot volcanic fluid being exsolved from the magma or by the heat of the magma itself. The heated edifice is demagnetized, and the magnetic field due to the demagnetization manifests as a positive anomaly in the north and a negative anomaly in the south. When magma descends, an opposite anomaly is observed.

The spatial pattern of the negative-north and a positivesouth anomalies observed at Shinmoe-dake suggests magnetization, or cooling of the volcanic edifice. Below, we examine whether the observed magnetization can be explained by the cooling of the extruded lava in the summit crater of Shinmoe-dake.

Cooling solely by thermal diffusion is implausible because only a 5-m-thick layer of extruded lava can be cooled in 6 months, assuming a typical conditions. Cooling by water of rainfall is one alternative theory. The amount of lava in the crater is estimated to be $1.5 \times 10^{7} \mathrm{~m}^{3}$ (Nakada et al., 2013). The mass of lava accumulated in the summit crater of Shinmoe-dake is $3.8 \times 10^{10} \mathrm{~kg}$, assuming typical density of andesitic lava of $2.5 \mathrm{~g} / \mathrm{cm}^{3}$. The amount of heat $E_{L}$ needed to be removed to cool the lava is given by:

$$
E_{L}=\left(C_{p}\left(T_{i}-T_{f}\right)+h_{L}\right) M_{L},
$$

where $C_{p}$ is the melt-crystal specific heat, $T_{i}$ and $T_{f}$ are the initial and final temperatures, $h_{L}$ is the latent heat of crystallization, and $M_{L}$ is the mass of the lava. A typical temperature of andesitic lava at the time of eruption is 900$950^{\circ} \mathrm{C}$ (Suzuki et al., 2013a). The melt-crystal specific heat and latent heat of crystallization of lava are $1.3 \times 10^{3} \mathrm{~J} / \mathrm{kg} / \mathrm{K}$ and $2.1 \times 10^{5} \mathrm{~J} / \mathrm{kg}$, respectively. The heat necessary to cool the lava in the summit crater from the initial temperature of $950^{\circ} \mathrm{C}$ to the Curie temperature of $600^{\circ} \mathrm{C}$ is thus $2.5 \times 10^{16} \mathrm{~J}$. (Here, we have used the Curie temperature of magnetite.) The rainfall around Shinmoe-dake from May to October 2011 was approximately $3900 \mathrm{~mm}$ (Japan Meteorological Agency). We assume that the rainfall in the area of the summit crater contributes to the lava cooling in the crater. Since the diameter of the crater is $750 \mathrm{~m}$, the amount of rainfall there was $1.7 \times 10^{9} \mathrm{~kg}$. We assume that all of the rainfall in the crater contributes to lava cooling. The heat necessary to evaporate this amount of water is:

$$
E_{w}=\left(C_{w}\left(100-T_{a}\right)+h_{w}\right) M_{w},
$$

where $C_{w}$ is the specific heat of steam, $T_{a}$ is atmospheric temperature, $h_{w}$ is the latent heat of steam, and $M_{w}$ is the mass of the water. The specific heat and latent heat of steam are $4.2 \times 10^{3} \mathrm{~J} / \mathrm{kg} / \mathrm{K}$, and $2.3 \times 10^{6} \mathrm{~J} / \mathrm{kg}$, respectively. We assume $T_{a}=20^{\circ} \mathrm{C}$. The heat necessary to evaporate $1.7 \times 10^{9} \mathrm{~kg}$ of water is $4.5 \times 10^{15} \mathrm{~J}$. The heat necessary to cool the lava in the crater is 5-6 times larger than what is needed to evaporate all the rainfall in the summit crater between the two aeromagnetic observations.

Rainfall above the contour line of the bottom of the crater may have also contributed to lava cooling in the crater. The elevation of the bottom of the summit crater before the eruption was $1239 \mathrm{~m}$ above sea level, and the diameter of the contour line of $1250 \mathrm{~m}$ was approximately $1500 \mathrm{~m}$. The amount of rainfall water in this wider area is 4 times larger than the rainfall in the summit crater. In order for the rainfall outside the crater to help cool the lava in the crater, the permeability distribution near the top of the volcanic edifice must result in water falling around the crater being directed into the area where the lava was pooling. If this condition is satisfied, then more than $70 \%$ of the heat necessary to cool the lava can be explained.

We calculate the theoretical residual magnetic field assuming that all of the $1.5 \times 10^{7} \mathrm{~m}^{3}$ of lava in the summit crater acquires a certain value of magnetization by cooling. The lava is divided into elemental magnetization prisms, and the theoretical magnetic field is given by a sum of contributions from all the prisms. The best-fit synthetic residual magnetic field is obtained when we assume that the magnetization change in the crater is about $1.5 \mathrm{~A} / \mathrm{m}$ (Fig. 5, right).

It is surprising that the magnetization of the cooled lava in the crater matches the averaged magnetization in this area. As mentioned in Subsection 5.1, the expected magnetization intensity of lava extruded from Shinmoe-dake is higher than this value. One possible explanation for this reduced magnetization is that the summit area is covered with thick volcanic ash, which mainly cools in the air and acquires randomly directed magnetization, and thus causes reduced magnetization. The amount of rainfall may not be enough to fully magnetize the lava in the crater. In this case, it turns out that the assumption that the all the lava in the crater was fully magnetized is not correct. This would be another explanation for the low magnetization intensity of $1.5 \mathrm{~A} / \mathrm{m}$. If 20 to $70 \%$ of the lava is magnetized, then the expected magnetic intensity is 2 to $7.5 \mathrm{~A} / \mathrm{m}$, which is reasonable for the andesitic-dacitic magma of Shinmoe-dake.

\section{Conclusions}

We have conducted aeromagnetic surveys at Shinmoedake twice in 2011, using an unmanned autonomous helicopter. The average magnetization intensity around Shinmoe-dake is $1.5 \mathrm{~A} / \mathrm{m}$, suggesting that the volcanic edifice is covered with relatively new volcanic material, or has lost magnetic minerals by post-eruption alteration. The magnetization model shows a weakly-magnetized area extending to the north and northwest of Shinmoe-dake. This area may correspond to the magma supply path from the deep magma chamber to Shinmoe-dake. The differences in the total magnetic field observed between two observations show positive and negative magnetic anomalies in the south and north of the Shinmoe-dake edifice, respectively. The spatial pattern of the anomaly suggests lava cooling in the summit crater. The calculated magnetic anomaly, assuming completely cooled lava in the summit crater between the two aeromagnetic surveys, explains the observed anomaly. But the magnetic intensity that best explains the observation seems rather low. Lava cooling of $20-70 \%$ by rainfall in and around the summit area can explain the majority of the observed anomaly.

Acknowledgments. We thank T. Morishita, T. Kubono, J. Imai and other members of the Sky Operations division of YamahaMotor Co., Ltd for the operation of RMAX-G1. Y. Honda and K. Kajiwara at the Center for Environmental Remote Sensing, Chiba University, gave us valuable advice for helicopter opera- 
tions. We are grateful to A. Takagi and M. Ukawa for their funding assistance. We also thank the Japan Meteorological Agency and Kirishima-city, Kagoshima prefecture, for their support in field operations. Constructive comments by Dr. Tony Hurst and one anonymous reviewer helped significantly to improve the quality of the paper. This research is supported by the Programs of Special Coordination Funds for Promoting Science and Technology, and a Director's grant from the Earthquake Research Institute, University of Tokyo.

\section{References}

Akaike, T., Likelihood and Bayes procedure, in Bayesian Statistics, edited by J. M. Bernardo, M. H. deGroot, D. V. Lindley, and A. F. Smith, pp. 143-166, University Press, Valencia, Spain, 1980.

Bhattacharyya, B. K., Magnetic anomalies due to prism-shaped bodies with arbitrary polarization, Geophysics, 29, 517-531, 1964.

Hansen, P. C., Analysis of discrete ill-posed problems by means of the L-curve, SIAM Rev., 34(4), 561-580, 1992.

Hashimoto, T., T. Koyama, T. Kaneko, T. Ohminato, M. Yoshimoto, E. Suzuki, and T. Yanagisawa, Aeromagnetic survey using an unmanned autonomous helicopter over Tarumae volcano, Geophys. Bull. Hokkaido Univ., 75, 145-159, 2012.

Hildenbrand, T. G., J. G. Rosenbaum, and J. P. Kauahikaua, Aeromagnetic study of the Island of Hawaii, J. Geophys. Res., 98, 4099-4119, 1993.

Imakiire, T. and A. Ookawa, Source model of Kirishima Volcano based on GPS integrated analysis in volcanic region, J. Geospa. Infor. Author. Jap., 121, 183-188, 2011 (in Japanese).

Imura, R. and T. Kobayashi, Geological map of Kirishima volcano, Geological Survey of Japan, 2001 (in Japanese with English abstract).

International Association of Geomagnetism and Aeronomy, Working Group V-MOD, International Geomagnetic Reference Field: The eleventh generation, Geophys. J. Int., 183(3), 1216-1230, 2010.

Kagiyama, T., H. Utada, M. Uyeshima, F. Masutani, W. Kanda, Y. Tanaka, H. Masuda, H. Murakami, I. Shiozaki, M. Ichiki, T. Yukutake, T. Mogi, K. Amita, N. Oshiman, and M. Mishina, Resistivity structure of Middle and South-East part of Kirishima volcanoes, Bull. Volcanol. Soc. Jpn., 41, 215-225, 1996 (in Japanese with English abstract).

Kaneko, T., T. Koyama, A. Yasuda, T. Yanagisawa, M. Takeo, Y. Honda, and K. Kajiwara, Low-altitude remote sensing of volcanoes using unmanned helicopter: An example of aeromagnetic observation at IzuOshima, JGU Meeting 2010, V159-P007, 2010.

Kaneko, T., T. Koyama, A. Yasuda, M. Takeo, T. Yanagisawa, K. Kajiwara, and Y. Honda, Low-altitude remote sensing of volcanoes using an unmanned autonomous helicopter: An example of aeromagnetic observation at Izu-Oshima volcano, Japan, Int. Jour. Remote Sensing, 32, 1491-1504, 2011.

Kunaratnam, K., Simplified expressions for the magnetic anomalies due to vertical rectangular prisms, Geophys. Prospect., 29, 883-890, 1981.

Menke, W., Geophysical Data Analysis: Discrete Inverse Theory, 289 pp., Academic Press, San Diego, 1989.

Nakada, S., M. Nagai, T. Kaneko, Y. Suzuki, and F. Maeno, The outline of the 2011 eruption at Shinmoe-dake (Kirishima), Japan, Earth Planets
Space, 65, this issue, 475-488, doi:10.5047/eps.2013.03.016, 2013.

Nakao, S., Y. Morita, K. Goto, H. Yakiwara, S. Hirano, J. Oikawa, H Ueda, T. Kozono, Y. Hirata, H. Takahashi, M. Ichiyanagi, Y. Ohta, T. Matsushima, and M. Iguchi, Crustal deformation after the eruption on January, 2011 by continuous GPS observation in Kirishima Volcano, JGU Meeting 2012, SVC50-01, 2012.

Nakatsuka, T., Aeromagnetic anomalies over the area of Unzendake volcano, J. Geomag. Geoelectr., 46, 529-540, 1994.

Nakatsuka, T., Minimum norm inversion of magnetic anomalies with application to aeromagnetic data in the Tanna Area, Central Japan, J. Geomag. Geoelectr., 47, 295-311, 1995.

Okubo, A., Y. Tanaka, M. Utsugi, N. Kitada, H. Shimizu, and T. Matsushima, Magnetization intensity mapping on Unzen Volcano, Japan, determined from high-resolution, low-altitude helicopter-borne aeromagnetic survey, Earth Planets Space, 57, 743-753, 2005.

Okubo, A., W. Kanda, Y. Tanaka, K. Ishihara, D. Miki, M. Utsugi, T. Takayama, and M. Fukushima, Apparent magnetization intensity map on Sakurajima Volcano, Kyushu, Japan, inferred from low-altitude, high-density helicopter-borne aeromagnetic surveys, Tectonophysics, 478, 34-42, 2009.

Okubo, Y., R. J. Graf, R. O. Hanse, K. Ogawa, and H.Tsu, Curie point depths of the Island of Kyushu and surrounding areas, Japan, Geophysics, 53(3), 481-494, 1985.

Okuma, S., C. Stotter, R. Supper, T. Nakatsuka, R. Furukawa, and K. Motschka, Aeromagnetic constraints on the subsurface structure of Stromboli Volcano, Aerolian Islands, Italy, Tectonophysics, 478, 19-33, 2009.

Suzuki, H., The Observation-use UAV "RMAX G0-1", YAMAHA MOTER Technical Review, 2005-3, 39, 2005 (in Japanese with English abstract). Suzuki, Y., A. Yasuda, N. Hokanishi, T. Kaneko, S. Nakada, and T. Fujii, Syneruptive deep magma transfer and shallow magma remobilization during the 2011 eruption of Shinmoe-dake, Japan-Constraints from melt inclusions and phase equilibria experiments-, J. Volcanol. Geotherm. Res., 257, 184-204, 2013a.

Suzuki, Y., M. Nagai, F. Maeno, A. Yasuda, N. Hokanishi, T. Shimano, M. Ichihara, T. Kaneko, and S. Nakada, Precursory activity and evolution of the 2011 eruption of Shinmoe-dake in Kirishima volcanoinsights from ash samples, Earth Planets Space, 65, this issue, 591-607, doi:10.5047/eps.2013.02.004, 2013b.

Tanaka, Y., Eruption mechanism as inferred from geomagnetic changes with special attention to the 1989-1990 activity of Aso Volcano, $J$. Volcanol. Geotherm. Res., 56, 319-338, 1993.

Ueda, Y., A 3D magnetic structure of Izu-Oshima volcano and their changes after the eruption in 1986 as estimated from repeated airborne magnetic surveys, J. Volcanol. Geotherm. Res., 164, 176-192, 2007.

Utada, H., M. Neki, and T. Kagiyama, A study of annual variations in geomagnetic total intensity with special attention to detecting volcano magnetic signals, Earth Planets Space, 52, 91-103, 2000.

T. Koyama (e-mail: tkoyama@eri.u-tokyo.ac.jp), T. Kaneko, T. Ohminato, T. Yanagisawa, A. Watanabe, and M. Takeo 